\title{
Prevalence of Coronary Heart Disease Associated with HFE Mutations in Adults Attending a Health Appraisal Center
}

\author{
Jill Waalen, MD, MPH, Vincent Felitti, MD, Terri Gelbart, Ngoc J. Ho, MS, Ernest Beutler, MD
}

PURPOSE: Mutations of the HFE gene that cause hereditary hemochromatosis may be associated with an increased risk of cardiovascular disease. We examined the relation between two HFE mutations (C282Y and H63D), indicators of iron homeostasis, and the prevalence of coronary heart disease in a large population of white adults.

SUBJECTS AND METHODS: We conducted a cross-sectional study of 30,916 white adults aged 25 to 98 years who attended a health appraisal center and underwent screening for HFE mutations. Coronary heart disease and cardiovascular risk factors were ascertained by questionnaire and medical records.

RESULTS: Overall, 12\% (1798/15,362) of men and 7\% (1074/ $15,554)$ of women had a history of coronary heart disease. Of 10 HFE genotypes tested (five genotypes by sex), only men with the C282Y/H63D genotype (compound heterozygotes) had a significantly higher prevalence of coronary heart disease compared with men with no HFE mutations (odds ratio $=1.6$; $95 \%$ confidence interval: 1.1 to $2.4 ; P=0.01$ ) after adjusting for cardiovascular risk factors. Elevated serum ferritin levels ( $>250 \mathrm{ng} /$ $\mathrm{mL}$ ) were associated with a lower prevalence of coronary heart disease in men $(10 \%$ [255/2209] vs. $12 \%$ [1515/12,461] in controls, $P=0.008$ ), which was not significant after adjusting for use of aspirin and anticoagulants. There were no significant associations between elevated transferrin saturation in either men or women, or between elevated serum ferritin levels or HFE mutations in women, and the prevalence of coronary heart disease.

CONCLUSION: The results do not support a consistent association between HFE mutations or serum iron indicators and the prevalence of coronary heart disease. Am J Med. 2002;113: 472-479. ( 2002 by Excerpta Medica, Inc.
$\mathrm{T}$ here is substantial interest in the role of iron in coronary heart disease and other atherosclerotic diseases. However, studies of the relation between elevated iron levels, as determined by indicators including serum ferritin level and transferrin saturation, and cardiovascular disease have largely not supported this hypothesis (1-4).

As a genetic disease of iron overload, hereditary hemochromatosis provides an additional model to study the effects of iron in cardiovascular disease. The majority of people who are homozygous for the $845 \mathrm{G} \rightarrow \mathrm{A}(\mathrm{C} 282 \mathrm{Y})$ mutation of the hemochromatosis gene HFE, the major mutation associated with the disease, have elevated transferrin saturation and ferritin levels (5). Heterozygotes for this mutation, and homozygotes for another minor HFE mutation, $187 \mathrm{C} \rightarrow \mathrm{G}(\mathrm{H} 63 \mathrm{D})$, have lesser abnormalities

From the Department of Molecular and Experimental Medicine (JW, TG, NJH, EB), The Scripps Research Institute, La Jolla, California; and Department of Preventive Medicine (VF), Kaiser Permanente, San Diego, California.

Supported by grants DK53505-02 and RR00833 from the National Institutes of Health, Bethesda, Maryland, and supplemented with a grant from the Division of Nutrition and Physical Activity, Centers for Disease Control and Prevention, Atlanta, Georgia, and funds from the Stein Endowment Fund, San Diego, California.

Requests for reprints should be addressed to Jill Waalen, MD, MPH, Department of Molecular and Experimental Medicine, The Scripps Research Institute, 10550 North Torrey Pines Road, La Jolla, California 92037, or jwaalen@scripps.edu.

Manuscript submitted June 15, 2001, and accepted in revised form June 12, 2002. of iron metabolism (5). Data from three prospective studies have suggested an increased risk of incident cardiovascular disease and cardiovascular disease deaths among carriers of the C282Y mutation (6-8). Several case-control studies, however, have not found any significant associations between HFE mutations and cardiovascular disease (9-14). We studied the relation between HFE mutations and the prevalence of coronary heart disease in a cross-sectional study of more than 30,000 white adults attending a health appraisal center. We also examined the relation of elevated serum ferritin and transferrin saturation levels to HFE genotype and the prevalence of coronary heart disease.

\section{SUBJECTS AND METHODS}

The sample consisted of 30,916 white, non-Hispanic, adult patients aged 25 to 98 years who were attending the Health Appraisal Center at Kaiser Permanente, San Diego, California. All subjects gave informed consent to be screened for hemochromatosis by HFE genotyping. During any given 4 -year period, approximately $81 \%$ of Kaiser enrollees attend the center; all patients attending were offered the opportunity to participate in the study. Those who consented represented $46 \%$ of all white, non-Hispanic patients attending the center from May 1999 to August 2001. These subjects were slightly older (mean [ \pm SD] age, $58 \pm 14$ years) and more likely to be men (50\%) than were nonconsenting subjects during the same pe- 
$\operatorname{riod}(\mathrm{n}=35,792$; mean age, $51 \pm 16$ years; $45 \%$ men). Subjects who did or did not participate were similar in self-reported age- and sex-specific history of myocardial infarction (men: $4.6 \%$ vs. $4.0 \%$; women: $1.4 \%$ vs. $1.3 \%$ ) or in other conditions including hypertension, diabetes, obesity, or high cholesterol level. The study protocol was approved by Kaiser Permanente and The Scripps Research Institute institutional review boards.

Demographic information and medical history were obtained from a 400 -item questionnaire completed by all participants as part of a routine health appraisal examination. Patients recorded answers on forms that were read by an electronic scanning system (Scantron Corporation, Tustin, California). Electronic medical records containing International Classification of Diseases, Ninth Edition (ICD-9) diagnostic codes for Kaiser hospital admissions and medical services received outside of the Kaiser system from 1994 to 2001 were used to supplement the questionnaire data to ensure ascertainment of all coronary heart disease events. Questionnaire, laboratory, and medical record data were linked by unique patient identification numbers.

A subject was defined as having a history of coronary heart disease by a "yes" answer to either of the following questions on the health appraisal questionnaire: "Have you had a heart attack for which you were hospitalized for at least 3 days?" or "Do you have angina pectoris?"; or an ICD- 9 code 410 for acute myocardial infarction, code 412 for old myocardial infarction, code 413 for angina, or codes 411 or 414 for other ischemic heart disease in the medical record. For analyses of specific outcomes, history of myocardial infarction was defined as ICD-9 codes 410 or 412 in the medical record or a "yes" answer to the question on heart attack. History of angina pectoris alone was defined as ICD-9 code 413 in the medical record or a "yes" answer to the question on angina pectoris in subjects without a history of myocardial infarction.

Possible confounders were defined from questionnaire data, including smoking history (never smoker vs. ever smoker by response to "Have you ever smoked cigarettes?") and histories of diabetes, high cholesterol, and hypertension, defined by a "yes" answer to whether the patient had been diagnosed with the respective condition. Body mass index $\left(\mathrm{kg} / \mathrm{m}^{2}\right)$ was determined from height and weight measurements taken during the health appraisal visit. A cutoff of $30 \mathrm{~kg} / \mathrm{m}^{2}$ was used to define obesity.

Serum iron, transferrin saturation, and ferritin values were determined from blood samples obtained as part of the health appraisal. Serum iron levels were measured by the Ferrozine method (Sigma, St. Louis, Missouri) using a Hitachi 717 analyzer (Hitachi Instruments, Inc., San Jose, California). Total iron-binding capacity was measured by the same method after alumina adsorption. Transferrin saturation was calculated as serum iron divided by total iron-binding capacity. Serum ferritin level was measured by using the Centaur immunoassay system (Bayer Diagnostics, Tarrytown, New York). A transferrin saturation $>55 \%$ in men and $>45 \%$ in women, and a serum ferritin level $>250 \mathrm{ng} / \mathrm{mL}$ in men and $>200 \mathrm{ng} / \mathrm{mL}$ in women, were used to define elevated levels based on clinical criteria typically used in screening for iron overload (15-17).

Deoxyribonucleic acid (DNA) for analysis of HFE mutations was isolated from blood leukocytes using a QAIamp 96 Spin Blood Kit (Qiagen Inc, Santa Clarita, California). The DNA was amplified, and analysis for HFE mutations was carried out using allele-specific oligonucleotide hybridization (18). Patients were assigned one of six HFE genotypes representing all possible combinations of $\mathrm{C} 282 \mathrm{Y}$ and $\mathrm{H} 63 \mathrm{D}$ mutations, including no mutations, or wild type, designated as wt/wt. Carriers were defined as subjects having at least one of the specified mutation.

All analyses were performed separately by sex. Mean serum ferritin levels and transferrin saturation were compared among genotypes using analysis of variance with the Tukey test for multiple comparisons. Ferritin levels were $\log$ transformed to approximate a normal distribution. Chi-squared tests were used to evaluate the associations between HFE genotype, elevated transferrin saturation, and elevated ferritin levels, and a history of coronary heart disease. Separate multivariable logistic regression models were used to assess the effects of HFE genotype (five dummy variables representing six genotypes with $\mathrm{wt} / \mathrm{wt}$ as the comparison group), elevated transferrin saturation (dichotomous variable), and elevated serum ferritin levels (dichotomous variable) on coronary heart disease outcomes. All multivariable models adjusted for known cardiovascular risk factors, including age (in years) and histories of diabetes, smoking, hypertension, high cholesterol, and obesity (dichotomous variables). Possible interactions between HFE genotype and smoking status or hypertension were assessed by the BreslowDay test for homogeneity for Cochran-Mantel-Haenszel stratification, as well as by assessment of interaction terms in multivariable logistic regression models.

\section{RESULTS}

The sample consisted of 15,362 men (49.7\%) and 15,554 women (Table 1). Mean transferrin saturation and ferritin levels varied by HFE genotype, with highest values occurring in C282Y homozygotes (C282Y/C282Y), followed by compound heterozygotes (C282Y/H63D), H63D homozygotes (H63D/H63D), C282Y heterozygotes $(\mathrm{C} 282 \mathrm{Y} / \mathrm{wt}), \mathrm{H} 63 \mathrm{D}$ heterozygotes $(\mathrm{H} 63 \mathrm{D} / \mathrm{wt})$, and wild types (wt/wt) in both men and women (Table 1).

The overall prevalence of coronary heart disease was $12 \%(\mathrm{n}=1798)$ among men and $7 \%(\mathrm{n}=1074)$ among 
Table 1. Age, Transferrin Saturation, and Serum Ferritin Levels of White Adults Attending the Kaiser Health Appraisal Center, by HFE Genotype and Sex

\begin{tabular}{|c|c|c|c|c|c|c|c|c|}
\hline \multirow[b]{2}{*}{ Genotype } & \multicolumn{4}{|c|}{$\operatorname{Men}(\mathrm{n}=15,362)$} & \multicolumn{4}{|c|}{ Women $(\mathrm{n}=15,554)$} \\
\hline & $\begin{array}{c}\text { Number } \\
(\%)\end{array}$ & $\begin{array}{l}\text { Age } \\
\text { (years) }\end{array}$ & $\begin{array}{c}\text { Transferrin } \\
\text { Saturation } \\
(\%)^{\dagger}\end{array}$ & $\begin{array}{l}\text { Serum Ferritin } \\
\qquad(\mathrm{ng} / \mathrm{mL})^{\ddagger}\end{array}$ & $\begin{array}{c}\text { Number } \\
(\%)\end{array}$ & $\begin{array}{c}\text { Age } \\
\text { (years) }\end{array}$ & $\begin{array}{c}\text { Transferrin } \\
\text { Saturation } \\
\qquad \%)^{\dagger}\end{array}$ & $\begin{array}{l}\text { Serum Ferritin } \\
\qquad(\mathrm{ng} / \mathrm{mL})^{\S}\end{array}$ \\
\hline & & \multicolumn{2}{|c|}{ Mean $\pm \mathrm{SD}$} & $\begin{array}{c}\text { Mean (95\% } \\
\text { Confidence Interval) }\end{array}$ & & \multicolumn{2}{|c|}{ Mean $\pm S D$} & $\begin{array}{c}\text { Mean (95\% } \\
\text { Confidence Interval) }\end{array}$ \\
\hline C282Y/C282Y & $68(0.4)$ & $56 \pm 13$ & $63 \pm 21$ & $369(265-513)$ & $69(0.4)$ & $58 \pm 14$ & $52 \pm 22$ & $175(126-245)$ \\
\hline C282Y/H63D & $262(1.7)$ & $58 \pm 14$ & $39 \pm 13$ & $186(169-205)$ & $286(1.8)$ & $57 \pm 14$ & $33 \pm 13$ & $71(63-79)$ \\
\hline H63D/H63D & $357(2.3)$ & $58 \pm 13$ & $34 \pm 11$ & $139(128-152)$ & $372(2.4)$ & $59 \pm 13$ & $29 \pm 11$ & $61(55-67)$ \\
\hline C282Y/wt & $1467(9.6)$ & $59 \pm 13$ & $31 \pm 10$ & $119(113-124)$ & $1558(10.0)$ & $58 \pm 13$ & $27 \pm 10$ & $57(54-59)$ \\
\hline $\mathrm{H} 63 \mathrm{D} / \mathrm{wt}$ & $3642(23.7)$ & $58 \pm 13$ & $29 \pm 10$ & $117(114-120)$ & $3562(22.9)$ & $58 \pm 14$ & $25 \pm 9$ & $56(54-57)$ \\
\hline wt/wt & $9566(62.3)$ & $58 \pm 13$ & $27 \pm 9$ & $111(110-113)$ & $9707(62.4)$ & $58 \pm 14$ & $23 \pm 9$ & $53(52-54)$ \\
\hline
\end{tabular}

* Transferrin saturation values were available for 30,272 subjects (98\%; 15,029 men and 15,243 women). Serum ferritin levels were available for 29,465 subjects (95\%; 14,670 men and 14,795 women).

${ }^{\dagger}$ Mean transferrin saturation for all genotypes was significantly different from each other at $P<0.05$ by analysis of variance (ANOVA) with the Tukey test for multiple comparisons.

${ }^{\ddagger}$ Mean serum ferritin levels for all genotypes among men were significantly different from each other at $P<0.05$, except for C282Y/wt versus H63D/wt and wt/wt by ANOVA with the Tukey test for multiple comparisons.

${ }^{\S}$ Mean serum ferritin levels for all genotypes among women were significantly different from each other at $P<0.05$, except for $\mathrm{H} 63 \mathrm{D} / \mathrm{H} 63 \mathrm{D}$ versus all genotypes other than wt/wt, and C282Y/wt, $\mathrm{H} 63 \mathrm{D} / \mathrm{wt}$, and $\mathrm{wt} / \mathrm{wt}$ versus each other by ANOVA with the Tukey test for multiple comparisons. $\mathrm{wt}=$ wild type. 
women (Table 2). A history of myocardial infarction was also more common in men $(5 \%[\mathrm{n}=772])$ than in women $(2 \%[n=248])$; the prevalence of angina without a history of myocardial infarction was approximately $5 \%$ among men $(\mathrm{n}=830)$ and women $(\mathrm{n}=725)$. In univariate analyses, male C282Y/H63D compound heterozygotes had a significant 1.6-fold greater prevalence of coronary heart disease (17\% [44/262] vs. 11\% [1091/9566], $P=0.007)$ and myocardial infarction $(8 \%[21 / 262]$ vs. $5 \%$ [466/9566], $P=0.02$ ) compared with male wild types. No other significant associations were seen between HFE mutations and the prevalence of coronary heart disease, myocardial infarction, or angina alone, whether examined by carrier of either mutation, carrier of a specific HFE mutation, or a specific HFE genotype compared with sex-specific wild types (Table 2).

Among men, an elevated serum ferritin level $(>250$ $\mathrm{ng} / \mathrm{mL}$ ) was associated with a small but significant decrease in the prevalence of coronary heart disease $(10 \%$ [225/2209] vs. $12 \%[1515 / 12,461], P=0.008)$ and myocardial infarction ( $4 \%$ [84/2209] vs. $5 \%$ [662/12,461], $P$ $=0.003$; Table 3$)$. In contrast, among women, an elevated serum ferritin level $(>200 \mathrm{ng} / \mathrm{mL})$ was associated with a 1.3-fold higher prevalence of coronary heart disease $(P=0.02)$ and a 1.4-fold higher prevalence of angina $(P=0.005$; Table 3$)$. The associations were not significant when a cutoff of $500 \mathrm{ng} / \mathrm{mL}$ for an elevated serum ferritin level was used.

In a multivariable logistic regression model that adjusted for cardiovascular risk factors, the C282Y/H63D genotype in men remained significantly associated with the prevalence of coronary heart disease and myocardial infarction (Table 4). These odds ratios were not altered by inclusion of elevated transferrin saturation or serum ferritin level in the multivariable models.

In a separate multivariable logistic regression model, elevated ferritin levels continued to be associated with a lower prevalence of coronary heart disease in men (odds ratio $[\mathrm{OR}]=0.81 ; 95 \%$ confidence interval $[\mathrm{CI}]: 0.69$ to $0.95)$. When use of aspirin or anticoagulants - which were more common among men with a history of myocardial infarction $(75 \%$ [1355/1798]) than in those without $(35 \%[4787 / 13,564])$ and were associated with lower mean ferritin levels, perhaps due to chronic gastrointestinal blood loss-was added to the model as a dichotomous variable (yes/no for use of any of these drugs as ascertained by questionnaire), however, the association was no longer significant (Table 4).

Consistent with the univariate results, there were no significant associations in women between HFE genotype and the prevalence of coronary heart disease after adjusting for cardiovascular risk factors (Table 4). The positive association between elevated serum ferritin levels and coronary heart disease among women seen in univariate analysis was no longer significant in the multivariable lo-

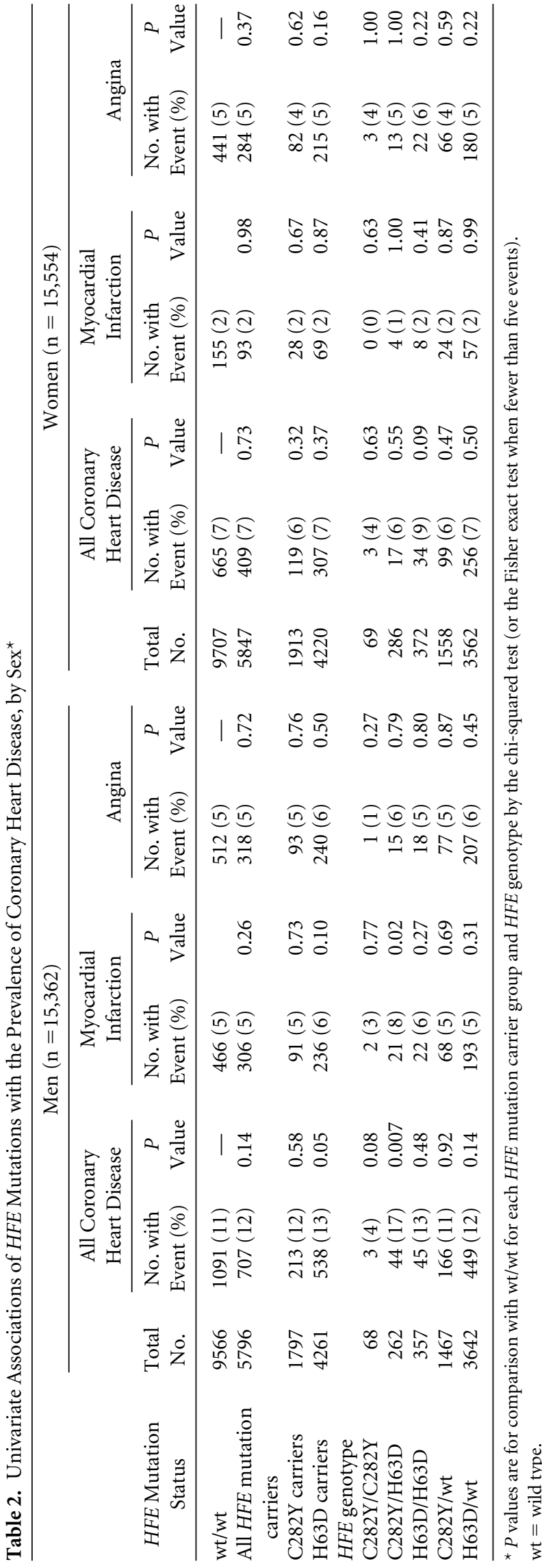

October 15, 2002 The American Journal of Medicine ${ }^{\circledR} \quad$ Volume 113 


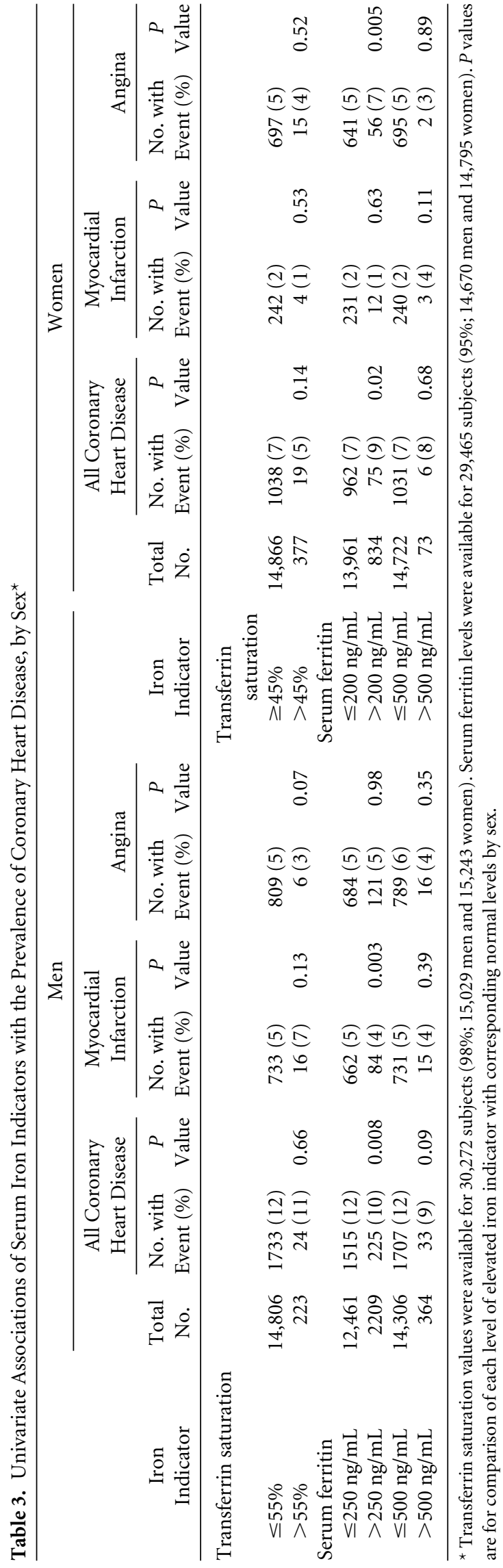

gistic regression model (Table 4). Stepwise addition of cardiovascular risk factors into the logistic regression model showed that in women the association was most altered by age (change in odds ratio from 1.3 to 1.0).

Finally, we tested whether smoking and hypertension affected the relation between HFE mutations and coronary heart disease. The prevalence of coronary heart disease was higher in subjects who smoked compared with those who did not smoke, and in those with hypertension compared with those without hypertension, among each genotype by sex (Table 5). These risk factors, however, did not significantly alter the odds ratios associated with any of the genotypes compared with wt/wt controls (Breslow-Day test of homogeneity of odds ratios for genotype vs. coronary heart disease stratified by smoking $[P$ $=0.63]$ and by hypertension status $[P=0.64])$. For example, the odds ratio for coronary heart disease in men did not differ significantly for the C282Y/H63D genotype compared with wt/wt among those who smoked $(\mathrm{OR}=$ $1.7 ; 95 \%$ CI: 1.2 to 2.6$)$ or did not smoke (OR $=1.4 ; 95 \%$ CI: 0.7 to 2.5 ; Table 5). There were also no significant $(P$ $>0.10$ ) interaction terms (genotype $\mathrm{x}$ smoking, and genotype $\mathrm{x}$ hypertension) in multiple logistic regression models.

\section{DISCUSSION}

In this large cross-sectional study of more than 30,000 white adults attending a health appraisal center, we found an increased odds of coronary heart disease among only one of 10 HFE genotype groups compared with sex-specific wild-type controls: male compound heterozygotes (C282Y/H63D) had a 1.6-fold increased odds of coronary heart disease after adjusting for age and other known cardiovascular risk factors. There were no significant associations among pooled carriers of the $\mathrm{C} 282 \mathrm{Y}$ or the $\mathrm{H} 63 \mathrm{D}$ mutation with coronary heart disease.

The finding of only one significant association and the lack of a dose response by number and type of HFE mutations argues against a strong association between HFE mutations and coronary heart disease outcomes, including myocardial infarction or angina. This is in contrast to the dose-response relation between serum iron indicators and the number of HFE mutations (C282Y $>\mathrm{H} 63 \mathrm{D})$ in both men and women. Additional caution in interpreting the one significant result is warranted by the relatively modest level of significance $(P=0.01)$ in this very large study in which multiple comparisons were performed, increasing the likelihood of finding a statistically significant result by chance.

If the $\mathrm{C} 282 \mathrm{Y} / \mathrm{H} 63 \mathrm{D}$ genotype in men is indeed associated with a true increase in the prevalence of coronary heart disease and myocardial infarction, the effect does not appear to be directly related to increased serum iron 
Table 4. Associations of HFE Genotype and Iron Status with the Prevalence of Coronary Heart Disease, by Sex, after Adjustment for Cardiovascular Risk Factors ${ }^{\star}$

\begin{tabular}{|c|c|c|c|c|}
\hline \multirow[b]{2}{*}{ Characteristic } & \multicolumn{2}{|l|}{$\begin{array}{c}\text { Men } \\
(\mathrm{n}=14,254)\end{array}$} & \multicolumn{2}{|l|}{$\begin{array}{c}\text { Women } \\
(\mathrm{n}=14,228)\end{array}$} \\
\hline & $\begin{array}{c}\text { Odds Ratio } \\
\text { (95\% Confidence Interval) }\end{array}$ & $\begin{array}{c}P \\
\text { Value }\end{array}$ & $\begin{array}{c}\text { Odds Ratio } \\
\text { (95\% Confidence Interval) }\end{array}$ & $\begin{array}{c}P \\
\text { Value }\end{array}$ \\
\hline \multicolumn{5}{|l|}{ HFE genotype } \\
\hline $\mathrm{C} 282 \mathrm{Y} / \mathrm{C} 282 \mathrm{Y}$ & $0.5(0.1-1.9)$ & 0.28 & $0.7(0.2-2.2)$ & 0.51 \\
\hline C282Y/H63D & $1.6(1.1-2.4)$ & 0.01 & $0.9(0.5-1.5)$ & 0.65 \\
\hline $\mathrm{H} 63 \mathrm{D} / \mathrm{H} 63 \mathrm{D}$ & $1.1(0.7-1.5)$ & 0.73 & $1.2(0.8-1.8)$ & 0.40 \\
\hline $\mathrm{C} 282 \mathrm{Y} / \mathrm{wt}$ & $1.0(0.8-1.2)$ & 0.80 & $0.9(0.7-1.1)$ & 0.36 \\
\hline $\mathrm{H} 63 \mathrm{D} / \mathrm{wt}$ & $1.1(0.9-1.2)$ & 0.29 & $1.0(0.9-1.2)$ & 0.94 \\
\hline wt/wt & 1.0 & & 1.0 & \\
\hline Elevated serum ferritin ${ }^{\dagger}$ & $0.8(0.7-1.0)$ & 0.01 & $0.9(0.7-1.1)$ & 0.31 \\
\hline $\begin{array}{l}\text { Elevated serum ferritin, adjusted } \\
\text { for aspirin and anticoagulant use }\end{array}$ & $0.9(0.8-1.1)$ & 0.19 & & \\
\hline
\end{tabular}

* Adjusted for age (years) and presence of diabetes, high cholesterol, smoking, hypertension, and obesity (body mass index $>30 \mathrm{~kg} / \mathrm{m}^{2}$ ) as dichotomous variables. Each of these risk factors was significantly associated with an increased risk of coronary heart disease in the multivariable models at $P<0.001$. Numbers of subjects indicate those included in the multiple logistic regression model; information on all cardiovascular risk factors was not available for all subjects.

${ }^{\dagger}$ Defined as $>250 \mathrm{ng} / \mathrm{mL}$ in men and $>200 \mathrm{ng} / \mathrm{mL}$ in women. wt $=$ wild type.

levels, as the relation was unchanged after adjusting for elevated transferrin saturation and serum ferritin levels. Other explanations for this observation, such as a possible link of HFE mutations to other genes that affect coronary heart disease, or effects of HFE mutations that are not reflected in transferrin saturation or ferritin levels, would need to be invoked.

The lack of a strong and consistent association between HFE mutations and coronary heart disease in this study is in contrast with the conclusions reached by two prospective studies, in which C282Y carriers (a group that included C282Y/C282Y, C282Y/H63D, and C282Y/wt genotypes) had a significantly increased risk of myocardial infarction (6,7). In a study that followed 1150 Finnish men aged 42 to 60 years for a mean of 9 years (6), C282Y carriers had a twofold increased risk of acute myocardial infarction (hazard ratio $=2.3$; $95 \%$ CI: 1.1 to $4.8 ; P=$ 0.04). Similarly, a case-cohort study using data from the Atherosclerosis Risk in Communities (ARIC) study showed a 3.4-fold increased odds (95\% CI: 1.3 to 9.4) of coronary heart disease in white carriers of the $\mathrm{C} 282 \mathrm{Y} \mathrm{mu}$ tation (7). In both studies, the association reached statistical significance $(P<0.05)$ only after adjustment for a large set of risk factors. Specific HFE genotypes incorporating both $\mathrm{C} 282 \mathrm{Y}$ and $\mathrm{H} 63 \mathrm{D}$ mutations were not tested in these studies.

The majority of studies examining the relation between HFE mutations and various cardiovascular disease endpoints have had negative results $(8-14)$. In a casecontrol study of postmenopausal women, Roest et al. (8) reported a significant association between the C282Y mutation and deaths from stroke or coronary heart dis- ease. However, consistent with our findings, the association was not significant for deaths from coronary heart disease alone. Likewise, several smaller case-control studies found no association between either $\mathrm{C} 282 \mathrm{Y}$ or H63D mutations and nonfatal myocardial infarction (9-12) or angiographically proven atherosclerosis $(13,14)$.

We observed that coronary heart disease and myocardial infarction were less common among men with elevated ferritin levels, whereas coronary heart disease and angina were more common among women with elevated ferritin levels. However, these associations did not persist after adjusting for aspirin and anticoagulant use in men and for age in women. This lack of a consistent association between elevated ferritin levels and the prevalence of coronary heart disease agrees with most other studies of this relation (19-21). Although an early study showed that Finnish men with ferritin levels $\geq 200 \mathrm{ng} / \mathrm{mL}$ had a moderately (twofold) increased risk of myocardial infarction (19), subsequent studies of similar design have failed to find a significant association among other white populations $(20,21)$. Our finding of no significant association between elevated transferrin saturation levels and coronary heart disease agrees with the results of several other studies (22-25).

Finally, our finding that smoking and hypertension did not affect the associations between HFE genotype and coronary heart disease agrees with the findings of the ARIC study (7), but is in contrast to the significant interactions with C282Y carrier status in another study (8). The apparently conflicting results may reflect population differences, as the latter study was limited to postmenopausal women. 


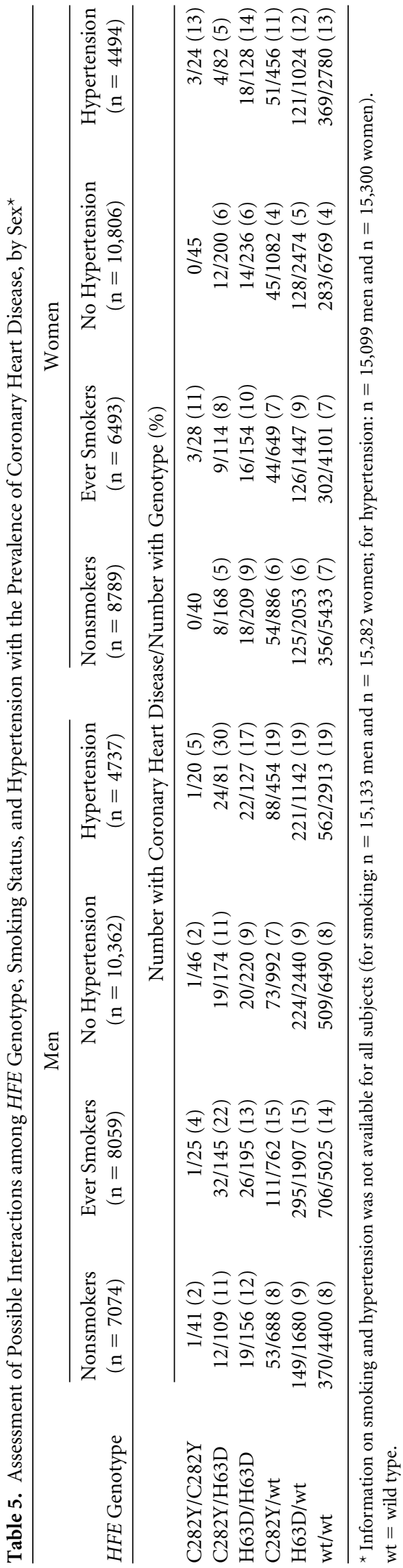

Limitations of our study include the cross-sectional design that limits analysis to nonfatal events and does not allow assessment of temporal relations. The inverse univariate association found between elevated ferritin levels and coronary heart disease among men illustrates the latter concern, because use of aspirin and anticoagulants confounded the apparent association.

Another potential limitation is the use of a sample from a health appraisal center, which may not represent the general population. However, the distribution of HFE genotypes and the prevalence of elevated serum ferritin levels and transferrin saturation were similar to those reported by surveys of the general population (26). In addition, the age- and sex-specific frequencies of relevant medical conditions were similar, or slightly higher, in our sample compared with those among white adults in population-based surveys for diabetes (4.5\% vs. 6.0\%) (27), obesity ( $28 \%$ vs. $19 \%)$ (27), and hypertension ( $30 \%$ vs. $33 \%)$ (28). Known cardiovascular risk factors were also strongly associated with coronary heart disease in our study, further supporting the validity of the methods used. Further evidence of the generalizability of the Health Appraisal Center sample has been reported (29).

In conclusion, we did not find a consistent relation between HFE mutations and coronary heart disease, with only one group in 10 (five genotypes by sex) having a modest, albeit statistically significant, increased prevalence compared with wild type. Our results are consistent with the majority of other studies examining this relation. Given that the one positive result involved C282Y/H63D compound heterozygotes, future studies examining the possible relation between HFE mutations and cardiovascular disease would benefit from genotyping for both C282Y and H63D mutations.

\section{REFERENCES}

1. Niederau C. Iron overload and atherosclerosis. Hepatology. 2000; 32:672-674.

2. Corti MC, Gaziano M, Hennekens CH. Iron status and risk of cardiovascular disease. Ann Epidemiol. 1997;7:62-68.

3. de Valk B, Marx JJM. Iron, atherosclerosis, and ischemic heart disease. Arch Intern Med. 1999;159:1542-1548.

4. Sempos CT, Looker AC, Gillum RF. Iron and heart disease: the epidemiologic data. Nutr Rev. 1996;54:73-84.

5. Beutler E, Felitti V, Gelbart T, et al. The effect of HFE genotypes in patients attending a health appraisal clinic. Ann Intern Med. 2000; 133:329-337.

6. Tuomainen TP, Kontula K, Nyyssonen K, et al. Increased risk of acute myocardial infarction in carriers of the hemochromatosis gene Cys282Tyr mutation: a prospective cohort study in men in eastern Finland. Circulation. 1999;100:1274-1279.

7. Rasmussen ML, Folsom AR, Catellier DJ, et al. A prospective study of coronary heart disease and the hemochromatosis gene (HFE) C282Y mutation: the Atherosclerosis Risk in Communities (ARIC) study. Atherosclerosis. 2001;154:739-746. 
8. Roest M, van der Schouw YT, de Valk B, et al. Heterozygosity for a hereditary hemochromatosis gene is associated with cardiovascular death in women. Circulation. 1999;100:1268-1273.

9. Calado RT, Franco RF, Pazin A, et al. HFE gene mutations in coronary atherothrombotic disease. Braz J Med Biol Res. 2000;33:301306.

10. Annichino-Bizzacchi JM, Saad ST, Arruda VR, et al. C282Y mutation in the HLA-H gene is not a risk factor for patients with myocardial infarction. J Cardiovasc Risk. 2000;7:37-40.

11. Hetet G, Elbaz A, Gariepy J, et al. Association studies between haemochromatosis gene mutations and the risk of cardiovascular diseases. Eur J Clin Invest. 2001;31:382-388.

12. Battiloro E, Ombres D, Pascale E, et al. Haemochromatosis gene mutations and risk of coronary artery disease. Eur J Hum Genet. 2000;8:389-392.

13. Franco RF, Zago MA, Trip MD, et al. Prevalence of hereditary hemochromatosis in premature atherosclerotic vascular disease. Br J Haematol. 1998;102:1172-1175.

14. Nassar BA, Zayed EM, Title LM, et al. Relation of HFE gene mutations, high iron stores and early onset coronary artery disease. Can J Cardiol. 1998;14:215-220.

15. Balan V, Baldus W, Fairbanks V, et al. Screening for hemochromatosis: a cost-effectiveness study based on 12,258 patients. Gastroenterology. 1994;107:453-459.

16. Adams PC, Chakrabarti S. Genotypic/phenotypic correlations in genetic hemochromatosis: evolution of diagnostic criteria. Gastroenterology. 1998;114:319-323.

17. Bassett ML, Leggett BA, Halliday JW, et al. Analysis of the cost of population screening for haemochromatosis using biochemical and genetic markers. J Hepatol. 1997;27:517-524.

18. Beutler E, Gelbart T. Large-scale screening for HFE mutations: methodology and cost. Genet Test. 2000;4:131-142.

19. Salonen JT, Nyyssönen K, Korpela H, et al. High stored iron levels are associated with excess risk of myocardial infarction in eastern Finnish men. Circulation. 1992;86:803-811.

20. Iribarren C, Sempos CT, Eckfeldt JH, et al. Lack of association between ferritin level and measures of LDL oxidation: the ARIC study. Atherosclerosis Risk in Communities. Atherosclerosis. 1998;139: 189-195.

21. Magnusson MK, Sigfusson N, Sigvaldason H, et al. Low iron-binding capacity as a risk factor for myocardial infarction. Circulation. 1994;89:102-108.

22. Sempos CT, Looker AC, Gillum RF, Makuc DM. Body iron stores and the risk of coronary heart disease. N Engl J Med. 1994;330: 1119-1124.

23. Baer DM, Tekawa IS, Hurley LB. Iron stores are not associated with acute myocardial infarction. Circulation. 1994;89:2915-2918.

24. Liao Y, Cooper RS, McGee DL. Iron status and coronary heart disease: negative findings from the NHANES I epidemiologic follow-up study. Am J Epidemiol. 1994;139:704-712.

25. Giles WH, Anda RF, Williamson DF, et al. Body iron stores and the risk of coronary heart disease [letter]. N Engl J Med. 1994;331: 1159-1160.

26. Looker AC, Johnson CL. Prevalence of elevated serum transferrin saturation in adults in the United States. Ann Intern Med. 1998;129: 940-945.

27. Mokdad AH, Bowman BA, Ford ES, et al. The continuing epidemics of obesity and diabetes in the United States. JAMA. 2001;286: $1195-1200$.

28. Ford ES, Giles WH, Dietz WH. Prevalence of the metabolic syndrome among US adults: findings from the Third National Health and Nutrition Examination Survey. JAMA. 2002;287:356-359.

29. Felitti VJ, Anda RF, Nordenberg D, et al. Relationship of childhood abuse and household dysfunction to many of the leading causes of death in adults. The Adverse Childhood Experiences (ACE) Study. Am J Prev Med. 1998;14:245-258. 